
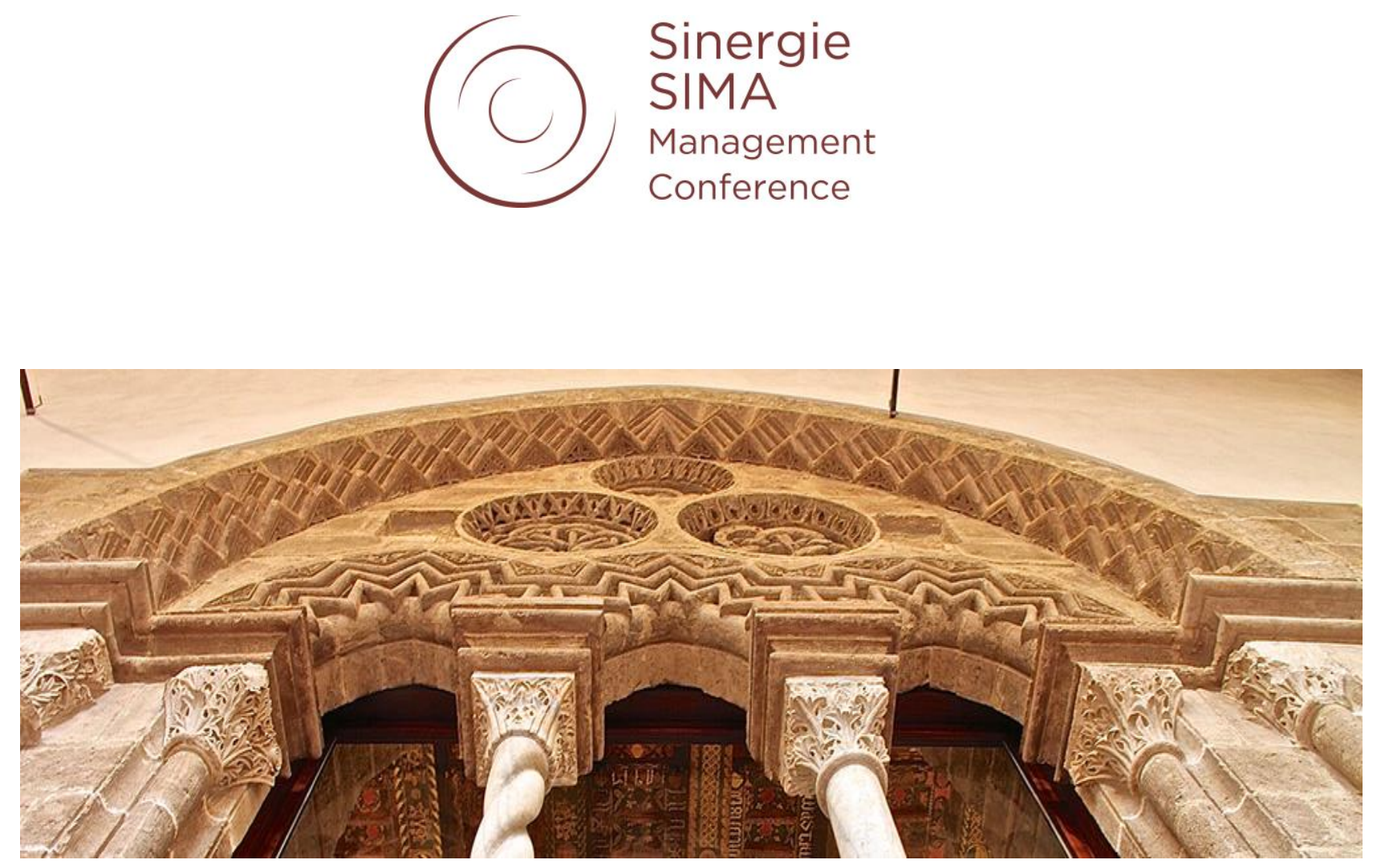

Source: University of Palermo

\title{
Leveraging intersections in management theory and practice
}

\section{Extended Abstracts}

University of Palermo

June 10-11, 2021 
Electronic Conference Proceedings of Sinergie - Sima Management Conference

Leveraging intersections in management theory and practice, Palermo, June 10-11, 2021

University of Palermo

ISBN 97888943937-9-8

The Electronic Conference Proceedings are published online on

http://www.sijm.it

(C) 2021 FONDAZIONE CUEIM

Via Interrato dell' Acqua Morta, 26

37129 Verona - Italy 


\title{
Purpose-driven Companies for Common Good: Managerial Characteristics and Dynamics
}

\author{
GiANLUCA GIONFRIDDO* VALENTINA CUCINO`ANDREA PICCALUGA^
}

Objectives. In recent years, several contributions have regarded the need to reimagine the current capitalist system (Henderson, 2020a), given the dysfunctionalities of the value creation process (Mazzucato, 2018) and the need to address environmental degradation, social injustices and economic inequalities (Pope Francis, 2015). As a matter of fact, empirical data clearly demonstrate how capitalism is globally accelerating income inequality, which reached its peak in OECD countries for the past half century, where the average income of the poorest 10\% of the population is about nine times lower than the average income of the richest 10\% of the population (OECD, 2021). About the environmental conditions of our planet, the data from the World Bank Group show that the carbon dioxide emissions in the atmosphere have been constantly raised since 1960, reaching the highest level of 36000 kiloton of CO2 in 2016 , which is the most recent year where data are available (World Bank Data, 2021).

Unsurprisingly, business is largely considered the main cause of such economic, social and environmental dysfunctions, due to the negative externalities coming from the business activities performed by companies (Mazzucato, 2018). The production of negative externalities, and the consequent market failure to solve today's societal challenges, traces back its foundation on the so-called "shareholder primacy" or "Friedman's dogma" (Friedman, 1970), which is the obligation of companies to maximize shareholder value (i.e., profits), even when this happens at the expense of other parties, that are broadly referred to as society and planet (Mayer, 2020). Thus, companies' activities of shareholder value maximization have been preferred to activities of societal value creation, leading to a profound crisis of our capitalistic system (Henderson, 2020a).

The consequent erosion of trust towards businesses is accelerating the design of new models and rules through which companies may again contribute to prosperity (Mayer, 2018). From this perspective, it is promising that significant changes have been observed in some companies - both large public companies and small ones, often family owned - that have adopted purpose-driven strategies, attributing more importance to value creation rather than shortterm profits (Asselle and Piccaluga, 2019). Indeed, some companies have implemented some concrete changes and are adopting more conscious and humanistic approaches (Rey et al., 2019). These companies are often referred to as Purpose-driven Companies (Rey et al., 2019), since their objective is "to produce profitable solutions to the problems of people and planet and not to profit from producing problems for people or planet” (Mayer, 2020, p. 6). More concretely, Purpose-driven Companies aim at improving social wealth and meeting social needs (De Clercq and Voronov, 2011; Lumpkin, Moss, Gras, Kato and Amezcua, 2013; Zahra, Gedajlovic, Neubaum and Shulman, 2009).

The fulfillment of companies purpose will also lead to the production of common good for society: eventually, this will lead to create the conditions for society members to achieve their personal goals (Argandoña, 1998). More concretely, we affirm that common good in society is built by the members of society; it is realized in society; and it is shared by members of society. In particular, companies are organizations that relate and interact with the rest of society and they generate common good by achieving their purposes.

Despite the recognized relevance of Purpose-driven Companies by different authors (Henderson, 2020b; Mayer, 2018; Rey et al., 2019), still few studies have emphasized management dynamics of Purpose-driven Companies and their role in society. Thus, this paper aims to answer the following research questions: what are the management dynamics of purposeful companies? How purpose-driven companies create common good for society? To address these research questions, we reviewed both purpose-driven companies (Harrison et al., 2020; Henderson, 2020b; Mayer, 2018; Rey et al., 2019) and common good literature (Hollensbe, 2014; Peeters and Martin, 2017). Based on this literature we identify the main dimensions (e.g. vision and alignment; effort and creativity; trust and relational contracts) that can be considered to characterize Purpose-driven Companies' actions.

Consequently, we elaborated a conceptual framework that combines these dimensions and applied it to 5 emblematic cases of Italian Purpose-driven Companies. Specifically, after a description and discussion of the above-

$\mathrm{PhD}$ Student in Innovation Management at Sant'Anna School of Advanced Stduies

e-mail: gianluca.gionfriddo@santannapisa.it

- Post-Doc Research Fellow of Management - Scuola Superiore Sant'Anna

e-mail: valentina.cucino@santannapisa.it

- Full Professor of Management - Scuola Superiore Sant'Anna

e-mail: andrea.piccaluga@ santannapisa.it 
mentioned literature, we analyze evidence from five medium and large Italian companies (Aboca, BB, Enel, Faac, Loccioni) which are well known for the adoption of purpose-oriented strategies.

Characteristics of PCs

Colin Mayer (2020) proposed eight characteristics of Purpose-driven Companies, which specifically regard company law, regulation, ownership, corporate governance, measurement, performance, finance and investment. In our research, we are interested in the four characteristics that are neither inherent to policy issues nor to measurement issues, but instead are directly accountable to the commitment of corporate managers and owners. Therefore, we take in consideration: 1) ownership, Purpose-driven Companies are characterized by anchor shareholders that guarantee long-term responsibility to fulfil corporate purposes; 2) corporate governance, the role of corporate boards in Purposedriven Companies is to define the corporate purpose and align it with managerial interests, ensuring that corporate values and strategy are directed towards the creation of long-term value creation for different parties, such as employees, communities, and environment; 3) corporate finance should allow Purpose-driven Companies to raise investments that generate positive, measurable social and environmental impact; 4) investment, Purpose-driven Companies have care to invest in other purpose-driven organizations belonging to the private, public or not-for-profit sector in order to jointly realize the above-mentioned business purpose of solving the problems of people and planet.

Dynamics of PCs

According to Henderson (2020b), the presence of a strong and shared corporate purpose is positively associated with the PdC ability to implement architectural innovation, which is referred to as "innovation that changes the architecture of a product or a system while keeping many of its components relatively unchanged" (Henderson and Clark, 1990). In particular, we believe that the output of architectural innovation applied to societal problems is the production of common good.

Henderson (2020b) suggested three managerial dynamics of Purpose-driven Companies that allow the implementation of architectural innovation. First, purpose drives both vision and alignment across the organization. Second, purpose increases engagement, effort and creativity across the organization. Third, purpose increases trust and relational contracts across the organization. Henderson (2020b) speculates that "the adoption of high-performance work systems requires the development of deep levels of trust across the organization or the development of relational contracts" (p.5), as in the empirical case of the Toyota production system. If present, a shared and authentic purpose may enhance company credibility and clarity, which in turn are likely to increase trust and foster relational contrasts across the organization.

These managerial dynamics are hypothesized to facilitate the capability of Purpose-driven Companies to see and seize architectural innovations, which we believe to have as output the production of common good.

Methodology. We validated the elements of Purpose-driven Companies and their relations by conducting an inductive, exploratory approach in our empirical analysis (Lee et al., 1999). On the basic principles of theoretical sampling (Eisenhardt, 1989), we searched for the units for research, based on characteristics or attributes that are important to the evaluation (Yin, 2018): firms that, in Italy, have two of the three characteristics analysed in the previous literature 1) small family businesses or joint-stock companies large part of shares where the shares are held by foundations or by families that perpetuate the purpose 2) companies that clearly express a long-term value creation in their mission 3) companies that attract sustainable and/or ethical funding.

As mentioned above, we have selected five companies based on the presence of two of these three characteristics: 1) small family businesses or joint-stock companies' large part of shares where the shares are held by foundations or by families that perpetuate the purpose 2) companies that clearly express a long-term value creation in their mission 3) companies that attract sustainable and / or ethical funding. Based on the criteria analysed above, we select 5 companies. In particular, ABOCA is a family company where the mission of creating long-term value for all stakeholders is shared. Loccioni is a family company that has received several sustainable / ethical loans and has a clear vision of long-term value creation for all stakeholders. Enel is a joint stock company that has adopted a Creating Shared Value approach, shared within the company and externally. BB is a company very focused on long-term value creation for all stakeholders and in particular between employees and the local context. Finally, FAAC is the company that established a TRUST FAAC fund given by the diocese.

Given the aim of this paper (i.e. how purposeful companies create common good and what are the management dynamics of purposeful companies), we adopted a methodology that has a confirmatory aim (Casprini et al., 2014). This approach led us to examine the rich body of data collected, thus building and refining the theory from the case study data (Eisenhardt, 1989). More specifically, we validated our data by conducting an inductive and confirmatory approach in our empirical analysis (Lee et al., 1999). Confirmatory approaches tend to confirm a researcher's preconceived notions and they are well recognized in the literature (Ruddin, 2006; Yin, 2018).

\section{Findings.}

Purpose drives Vision and Strategic alignment.

Loccioni is a family-owned for-profit company founded in 1958 by Enrico Loccioni and his wife, Graziella. From an artisan company that operated in local markets, Loccioni became a well-structured business operating in international markets. The key dynamic that allowed Loccioni to not lose its identity and vision during its growth is a strong commitment towards a shared purpose, as declared by the current CEO, Enrico Loccioni. 
In addition, pursuing a pro-social purpose enables Loccioni both to seize new business opportunities that competitors may miss (Porter, 2019) and to generate common good by implementing architectural innovations (Henderson, 2020b). For instance, their project "2 Km di futuro" initially originated from the necessity to create public value for the fluvial area where the power park of Loccioni stands, close to the river Esin. By reinvesting their profits, Loccioni successfully realized a laboratory of social innovation and design that allowed to generate hydropower for the Loccioni industrial sites, as well as to deliver common goods for the entire local community, such as river safety, a new cycle path and a renewed landscape design (Loccioni, 2021).

In the case of ENEL, the largest global private company in the sector of renewable energy, the business model has been fully built around the purpose of solving the challenge of climate change by producing green energy, expressed in the company's purpose statement of "Open Power for a brighter future. We empower sustainable progress."

Directly from this purpose it derives the company vision through which the around 70.000 employees are strategically aligned.

Purpose drives Engagement, Effort and Creativity

Purpose increases engagement, effort and creativity throughout the organization. This dynamic refers to the increased intrinsic motivation of employees resulting from the alignment between employees' personal values with corporate values. This dynamic is evident in all the cases highlighted, but has particular emphasis in two cases.

The first is ABOCA, an Italian healthcare company that deals with health care through $100 \%$ natural products that respect the body and the environment. ABOCA replicates the natural logic to preserve the health of the planet and man. In order to demonstrate its orientation to employees and external stakeholders, it chooses to become a Benefit Company, a new legal form of business, introduced in 2016 in Italy, the first country in the world after the United States.

Aboca tries to stimulate the involvement of employees in various ways, both by updating employees on the evolution in terms of results, strategy and objectives, and by meeting a representative of the workers to explain the relevance of the transition to a "purposeful" company action strongly desired by CEO Massimo Mercati. It is stated in ABOCA's annual report:

Indeed, ABOCA is committed to creating a positive and inclusive work environment by focusing on well-being a) financial, offering over 720,000 euros in company bonuses in 2019 b) physical, offering a smart working program for employees who needed it, c) professional and social, offering 150,000 hours of training and on the job training to employees of all levels but also d) tracing aspects such as company benefits, health and safety of workers, opportunities for professional development.

The second is FAAC, an Italian company specializing in automation for gates and barriers, automatic entrances and doors, parking and access control. In particular, FAAC invests in the future of its employees and the contexts in which it operates. FAAC's hiring strategies strive to create attractive career plans for young people, shunning recommendations or political influences. This helps to create long-term sustainability, where employees feel responsible for the longevity of the company in an environment free from short-term personal productivity logics. And the serenity of the work environment generates wealth for the company as demonstrated by the economic results of the last 7 years, which show a marked increase in turnover, which went from 283 million euros in 2012 to 460 million euros in 2019.

Purpose drives Trust and Relational contracts

BB Spa is a Tuscan for-profit manufacturing company that produces high-quality clothing accessories for the fashion industry. His founder and current CEO, Marco Bartoletti, gave to the company the purpose of restoring dignity to vulnerable people by providing them long-term employment. To achieve it, Marco Bartoletti hires terminally ill, disabled, autistic and fragile people that work together and pursue the same shared purpose. This established a work environment characterized by strong trust and relationship of reciprocity among employees.

Alongside with internal trust between employees, purpose may also drive trust between owners of the company and managers, as in the case of the industrial group FAAC, which is a multinational group that is totally owned by the diocese of Bologna. In 2015, the cardinal Carlo Caffarra entrusted the management of the entire company to three trustees that are in charge of the strategic decisions of FAAC.

Integral Human Development

The literature on purpose-oriented companies has shown that purpose a) drives both vision and alignment within the organization b) increases engagement, effort and creativity across the organization c) increases trust and relational contracts within the organization. However, the analysis of the cases reveals a still little investigated aspect of the companies concerned. The orientation towards a new business model, in fact, aims to create an integral human development of the person (Turkson, 2018; Mongelli, 2018). The integral human development of the person is the holistic development of the human person, which covers all aspects of life: social, economic, political, cultural, personal and spiritual. It promotes the dignity of the human person, equality between each person and the common good of all people in the community.

Research limits. This study also has limitations. Indeed, we analysed a limited sample of 5 medium and large Italian companies, but this represents a first version of the research that will be enriched with more cases. We also did not analyse with a quantitative approach the presence of the managerial dynamics under investigation and the 
production of common good. Further research may contribute to investigate the type of architectural innovations implemented by Purpose-driven Companies and to evaluate how they produce common good with a quantitative approach.

Practical implications. This study offers important practical implications for managers and entrepreneurs. First, based on our analysis, we argue that maximizing profit can no longer be the only one of those running a business. The purpose of a company is to become aware of the great responsibility towards its employees, the environment and more generally in the community. More concretely, the company's purpose is "to save the world and its community". (Henderson, 2020a). Second, the model proposed by purpose-oriented firms does not presuppose the absence of profit, but binds them to society (Henderson, 2020b). Indeed, in many cases, companies pursue profits and implement community benefits (for example, as examples of corporate philanthropy illustrate) (Hollensbe, 2014). Finally, focusing on purpose therefore poses the challenge for all businesses in terms of promoting the common good (Daly and Cobb, 1994) by aiming solely to provide products and services for the benefit of the community (Hollensbe, 2014).

Originality of the study. Since only a few management studies concretely analyse cases of Purpose-driven Companies which generate common good, in this study, we attempt to investigate their characteristics and managerial dynamics in a number of emblematic cases. Specifically, we analyse evidence from five medium and large Italian companies (Aboca, BB, Enel, Faac, Loccioni), which are well known for the adoption of purpose-oriented strategies.

The study is still ongoing, however it represents one of the first empirical analyzes of purpose-driven companies. Our analysis reveals an element that has not yet been investigated in the literature of Purpose-driven Companies: "Integral Human Development". More concretely, in order to combine the common good and the business, it is necessary to start from the needs of the people and the needs of the people are naturally and intrinsically ethical and social: therefore, if satisfied, they allow companies to generate the common good. The companies shown in this study are proof that the orientation towards the goal guides towards the integral development of the person: BB protects fragile employees, Loccioni creates schools for local children, Aboca creates natural medicines for the natural health of the person, Faac donates profits to poor people to reintegrate them and Enel creates clean energy to allow mankind to continue to thrive on earth.

Key words: Purpose-driven Companies; Common Good; Integral Human Development

\section{References}

ARGANDOÑA A. (1998), "The stakeholder theory and the common good”, Journal of business ethics, vol. 17, pp.1093-1102 ASSELlE M., PICCALUGA A. (2019), Sorella Economia. Edizioni Porziuncola.

CASPRINI E., PUCCI T., ZANNI L. (2014), "Business model shifts: a case study on firms that apply high technology to cultural goods", Technology Analysis \& Strategic Management, vol. 26, pp. 171-187.

DALY H.E., COBB J.B. (1994), For the common good: Redirecting the economy toward community, the environment, \& a sustainable future. Beacon Press.

DE CLERCQ D., VORONOV M. (2011), "Sustainability in entrepreneurship: A tale of two logics”, International Small Business Journal, Vol. 29, pp. 322-344.

EISENHARDT K.M. (1989), "Building Theories from Case Study Research”, Academy of Management Review, vol. 14, pp. 532550 .

FRANCIS P. (2015), Encyclical letter 'Laudato Sì', Vatican City: Libreria Editrice Vaticana

FRIEDMAN M. (1970). "A Friedman doctrine: The social responsibility of business is to increase its profits", The New York Times Magazine, vol. 13, pp. 32-33.

HARRISON J.S., PHILLIPS R.A., FREEMAN R.E. (2020), “On the 2019 Business Roundtable Statement on the Purpose of a Corporation", Journal of Management, vol. 46, pp.1223-1237.

HENDERSON R.M., CLARK K.B. (1990), "Architectural innovation: The reconfiguration of existing product technologies \& the failure of established firms", Administrative science quarterly, n. 35, pp. 9-30.

HENDERSON R. (2020a), Reimagining capitalism in a world on fire, Hachette UK.

HENDERSON R. (2020b). "Innovation in the 21st Century: Architectural Change, Purpose, \& the Challenges of Our Time", Management Science.

HOLLENSBE E., WOOKEY C., LOUGHLIN H., GEORGE G., NICHOLS V. (2014), "Organizations with purpose”, Academy of Management Journal, vol. 57,1 pp. 227-1234.

LEE T.W., MITCHELL T.R., SABLYNSKI C.J. (1999), "Qualitative research in organizational \& vocational psychology, 19791999”, Journal of Vocational Behavior, vol. 55, pp. 161-187.

LOCCIONI (2021), $2 \mathrm{~km}$ di futuro. www.loccioni.com, Accessed on 10 January 2021

LUMPKIN G.T., MOSS T.W., GRAS D.M., KATO S., AMEZCUA A.S. (2013), "Entrepreneurial processes in social contexts: how are they different, if at all?. Small Business Economics, vol. 40, pp. 761-783

MAYER C. (2018), Prosperity: better business makes the greater good. Oxford University Press.

MAYER C. (2020), "The Future of the Corporation \& the Economics of Purpose", Journal of Management Studies.

MAZZUCATO M., JACOBS M. (2016), Rethinking Capitalism, London: Wiley-Blackwell.

MAZZUCATO M. (2018), The value of everything: Making \& taking in the global economy, Hachette UK.

MONGELLI L., VERSARI P., RULLANI F., VACCARO A. (2018), "Made in prison: Integral human development in extreme conditions", Journal of Business Ethics, n. 152, pp. 977-995.

OECD. (2021), Income inequality (indicator)”, doi: 10.1787/459aa7f1-en Accessed on 06 January 2021 
PEETERS T., MARTIN X. (2017), "Strategies for knowledge use in R\&D \& their implications for innovative performance", $R \& D$ Management, vol. 47, pp. 47-60.

PORTER M.E. (1997), Competitive strategy. Measuring business excellence, New York: Free Press

PORTER M.E., KRAMER M.R. (2019), Creating shared value. In Gilbert G. Lenssen, N. Craig Smith, Managing sustainable business, Springer, Dordrecht, pp. 323-346.

REY C., BASTONS M., SOTOK P. (2019), Purpose-driven Organizations: Management Ideas for a Better World, Springer Nature, p. 138.

RUDDIN L.P. (2006), Y"ou can generalize stupid! Social scientists, Bent Flyvbjerg, \& case study methodology", Qualitative Inquiry, vol. 12, pp. 797-812.

SECOND VATICAN COUNCIL. (1965), “Gaudium et spes”, Acta Apostolicae Sedis vol. 58, 1966

THE WORLD BANK. (2021), CO2 emissions ( $k t$ ), www.data.worldbank.org, Accessed on 10 January 2021.

TURKSON P. K. C. (2018), "Pope Francis' integral human development: a proposal for inclusive growth", Journal of Humanities Management, vol. 2, pp. 199-209.

ZAHRA S.A., GEDAJLOVIC E., NEUBAUM D.O., SHULMAN J.M. (2009), “A typology of social entrepreneurs: Motives, search processes \& ethical challenges", Journal of Business Venturing, vol. 24, pp. 519-532.

YIN R.K. (2018), Case study research and applications. 6th edition. Los Angeles: SAGE Publications Inc. 